\title{
A SOCIALIZAÇÃO HUMANA E A INTERNALIZAÇÃO DA CULTURA
}

\section{Resumo:}

O presente trabalho consiste em um estudo sobre a socialização humana e a internalização da cultura, no qual, analisa-se os diferentes processos de socialização e as determinações sociais que os envolvem. Percebe-se que a socialização está mediada pela coerção das diferentes instituições sociais, bem como pela ideologia presente nestas instituições. Neste sentido, a compreensão da socialização humana passa pelo debate entre cultura e sociedade, pela influência desta sociedade nos processos de socialização e pelos determinantes históricos, sociais e simbólicos que envolvem os processos de socialização.

Palavras-chave: Educação; Cultura; Socialização.

\begin{abstract}
:
This paper aims at the study on the human socialization and the cultural internalization in which it is analyzed the different processes of socialization and the social determinations that involve them. It is perceived that socialization is mediated by the coercion of the varied social institutions, as well as by the ideology within these institutions. In this sense, the understanding of the human socialization passes through the debate between culture and society, through the influence of this society in the socialization processes, and through simbolical, social and historical determiners that involve them.
\end{abstract}

Key-words: Education, Culture, Socialization.

\section{1 - A socialização humana}

Socializar é interiorizar os conceitos, valores, crenças de determinada cultura, é o indivíduo construir para si um mundo histórico, humano, rodeado de significações. É a cultura em suas relações de interação entre os homens e a natureza que irá instituir a possibilidade de construção deste mundo histórico. Segundo Vaz (1966) a cultura possui um caráter objetivo e outro subjetivo, sendo que a face objetiva da cultura são as obras e a produção material do homem, e é no exercício do ato de criação cultural que o homem se realiza e emerge para o

\footnotetext{
${ }^{1}$ Mestre em Educação Brasileira - Faculdade de Educação / UFG. Professora do curso de Pedagogia - CAJ /UFG. e-mail: Suelylimajatai@yahoo.com.br
} 
Ztinerarius

Teflectionis
Revista Eletrônica de Educação do Curso de Pedagogia do Campus Avançado de Jataí da Universidade Federal de Goiás [Vol I - n.2 ] [jan/jul] [ 2006 ]

espaço humano da consciência de si mesmo. É neste espaço humano que o homem exprime a cultura subjetiva. Ele concebe a cultura como social e histórica, é o próprio sentido do homem no mundo e por isto ela é, também, humanizadora.

A cultura se constitui tanto no trabalho - em seu caráter objetivo - quanto em símbolos, regras, valores, ações, modo de ver e de ser no mundo - em seu caráter subjetivo - neste sentido ela se cria, se recria, se forma, se transforma, se externaliza, se objetiva e principalmente, se universaliza. O caráter universal da cultura ${ }^{2}$, que possibilita ao homem "ser" humano, é que gera a possibilidade de socialização, de interiorização do conhecimento produzido pelas diferentes sociedades. Um mundo humano construído como um mundo de significações e valores.

Para Berger e Luckmann (1985), qualquer estudo teórico sobre sociedade deve abranger seus aspectos objetivos e subjetivos, pois estar em sociedade significa participar de sua dialética.

O ponto inicial deste processo é a interiorização, a saber a apreensão ou interpretação imediata de um acontecimento objetivo como dotado de sentido, isto é, como manifestação de processos subjetivos de outrem, que desta maneira torna-se subjetivamente significativo para mim. (BERGER E LUCKMANN, 1985, p. 174)

A interiorização a que os autores se referem é o momento em que a objetivação do outro passa a ter significado, torna-se dotada de sentido para o indivíduo. Esta interiorização, para eles, constitui a base da compreensão entre os homens bem como a apreensão do mundo como realidade dotada de sentido. Esta compreensão possibilita ao indivíduo assumir o mundo no qual os outros vivem e de certa forma até recriá-lo.

Neste sentido, segundo Berger e Luckmann, a forma complexa de interiorização possibilita ao indivíduo não só compreender o outro, mas também o mundo em que vive, passando desta forma a participar cada qual do ser do outro. O indivíduo só se tornará membro da sociedade após realizar este grau de interiorização subjetiva. A este processo os autores denominam de socialização e a definem como ampla e consistente introdução de um indivíduo no mundo objetivo de uma sociedade.

Ressalta-se aqui que essas relações de interação em sociedade estarão mediadas pela coerção das diferentes instituições sociais, podendo, neste sentido, ser mediada pela ideologia presente nestas instituições. O processo de socialização, neste contexto, passa por diferentes 
determinações e a sua compreensão implica o desvelar de todas as determinações que a envolvem, principalmente as relações de interação do homem com o outro e ao mesmo tempo em sociedade.

Assim, a compreensão da socialização humana passa pelo debate entre cultura e sociedade, pela influência desta sociedade nos processos de socialização, e pela compreensão da socialização primária e secundária (Berger e Luckmann, 1995), bem como pelos determinantes históricos, sociais e simbólicos que envolvem os processos de socialização.

\section{1 - Cultura e sociedade nos processos de socialização}

Socialização é o momento de troca de experiências e saberes entre indivíduos, é quando se aprende a ser humanos. É um processo de interação que só se efetiva em sociedade, na participação e convivência com o outro. O estudo da socialização é um campo de estudos da sociologia e da antropologia, é um campo de debates que, dado a sua complexidade, não foi ainda amplamente discutido no campo das ciências sociais, como afirma Brandão (2001).

A socialização do homem pode ser considerada como um campo da antropologia social. Segundo Da Matta (1987), o estudo da antropologia social possibilita ao homem o conhecimento sobre si mesmo; o homem é tudo que se manifesta, na sociedade e na sociabilidade.

Para esse autor, os estudos antropológicos centrados na concepção biológica do homem revelam uma visão utilitarista da cultura e da sociedade ${ }^{3}$. Para ele, é preciso considerar sociedades e culturas e não homens individuais - é preciso universalizar a sociedade. $\mathrm{O}$ autor considera a necessidade de se pensar o mundo social, pois ele é um fenômeno coletivo.

Neste sentido, compreende-se que a universalização da cultura só se efetiva no processo de reconhecimento do outro, e não na individualidade, a humanização do homem se dá em coletividade. Entretanto, a cultura perde seu caráter de universalidade em função da individualização do homem que pode ocorrer tanto nas relações do homem no trabalho quanto nas relações de socialização em sociedade. Nesta perspectiva, quando Da Matta (1987) faz

\footnotetext{
${ }^{2}$ Quando a cultura institui o caráter de genericidade ao homem, passando do domínio da necessidade para o domínio da liberdade (Vaz, 1966), possibilitando o reconhecimento tanto de si, quanto do outro nas relações sociais, ela adquire o caráter de universalidade.

${ }^{3}$ Para Da Matta (1987), na concepção biológica, este desenvolvimento se deu por fatores externos, influências do meio - modificações do meio ambiente, que levaram o homem a inventar instrumentos para suprir suas necessidades.
} 
referência à importância do social na compreensão do homem em sociedade, compreende-se que a origem do homem não se dá por fatores externos, mas são determinações históricas e sociais que o levam ao processo de desenvolvimento.

É com esta visão que o autor nos conduz às possibilidades de socialização entre os homens. Para tanto, ele propõe uma diferenciação entre sociedade e cultura, demonstrando que sociedade é uma organização ordenada onde atua a coletividade; no entanto, nesta coletividade, pode não existir uma tradição. Tradição, segundo o autor, é cultura, possui movimento e é repassada de uma geração à outra. Já a cultura, para Da Matta (1987), é a produção de uma dada sociedade, tanto material quanto espiritual; é a forma como essa sociedade se organiza e produz sua arte, sua música. O que vai permitir que uma dada sociedade se diferencie de outra é a cultura - nela existe uma tradição. Ter tradição é vivenciar as regras de sua sociedade com consciência.

Sem uma tradição, uma coletividade pode viver ordenadamente, mas não tem consciência do seu estilo de vida. E ter consciência é poder ser socializado, isto é, é situar-se diante de uma lógica de inclusões necessárias e exclusões fundamentais, num exaustivo e muitas vezes dramático diálogo entre o que somos (ou queremos ser) e aquilo que os outros são e, logicamente, nós não devemos ser" (DA MATTA, 1987, p. 48)

Da Matta (1987) nos mostra, então, que a base do processo de socialização está na sociedade e em sua tradição ou cultura. Como dissemos anteriormente, socialização é um processo de interação que só se efetiva em sociedade, e, quando Da Matta (1987) diz que ter tradição é vivenciar as regras de sua sociedade com consciência, é poder ser socializado, compreende-se que este processo é possível nas diferentes sociedades estudadas no campo da antropologia. No entanto, esta conscientização, em determinadas condições, não se efetiva. É o que ocorre nas sociedades capitalistas, na qual as diferentes relações sociais no trabalho levam o indivíduo a uma individualização ${ }^{4}$.

O homem, como ser genérico, se socializa nas relações com outros homens e em sociedade. A individualização compromete sua socialização, já que esta depende da interação

\footnotetext{
${ }^{4} \mathrm{O}$ conceito de indivíduo foi discutido por ADORNO E HORKHEIMER (1973, p.52) onde os autores afirmam que o indivíduo surge quando estabelece o seu eu, a sua autoconsciência. No entanto, quando este indivíduo perde sua autoconsciência, ele si individualiza. A perda dessa consciência ocorre, no escopo da sociedade nas relações de trabalho que conduzem esse indivíduo à alienação, bem como aos processos de socialização mediados pela ideologia presente na mídia e nos meios de comunicação. É neste contexto que o indivíduo se individualiza.
} 
com o outro, em sociedade. Se, para Da Matta (1987), a sociedade é uma organização ordenada da coletividade, vale compreender como essa organização se deu historicamente.

A compreensão do conceito de sociedade levantado por Adorno e Horckeimer (1973) veio evoluindo historicamente, e embora em linhas gerais poderia ser definida como um “conjunto de homens, com grupos de diversas dimensões e significados, que compõe a humanidade", esta definição, para eles, não abarca todas as determinações implícitas na definição de sociedade, que para eles é

uma espécie de contextura formada entre todos os homens e na qual uns dependem dos outros, sem exceção; na qual o todo só pode subsistir em virtude da unidade das funções assumidas pelos co-participantes, a cada um dos quais se atribui, em princípio, uma tarefa funcional; e onde todos os indivíduos, por seu turno, estão condicionados, em grande parte, pela sua participação no contexto geral. (ADORNO E HORCKEIMER, 1973, p. 25)

Neste conceito percebe-se como é implícita a interdependência entre os indivíduos. A compreensão do todo da sociedade, segundo os autores, depende mais das funções assumidas pelos indivíduos envolvidos, e as leis subjacentes a este processo, do que dos elementos e suas descrições. Paralelo às reflexões sobre o conceito de sociedade, os autores fazem inferências sobre a socialização humana, dizendo que:

As formas de socialização - e, sobretudo, a socialização dos indivíduos num Estado organizado e controlado - manifestaram-se precisamente, ao pensamento que começava a refletir sobre a vida associada a algo que era substancial e presente, incontroverso e vigente sem contrastes, de modo que, diante do seu conteúdo - isto é, o processo vital da sociedade - a reflexão sobre o caráter da sociedade resolve-se, quase sem problemas, num exame das suas instituições coisificadas. (ADORNO E HORCKEIMER, 1973, p.26)

Adorno e Horckeimer vão, neste contexto, apresentar como foi a definição do conceito de sociedade, na visão de filósofos como Platão, Hobbes, Spencer, Hegel. Historicamente estes conceitos apresentam um caráter de dinamicidade e é este caráter de dinamicidade que possibilitará a socialização humana. A socialização é então um importante fator no processo de desenvolvimento tanto das sociedades quanto dos indivíduos que a compõem.

No entanto, o que estes autores nos apresentam como ressalvas, implícitas na citação acima, é que esta socialização é cercada de sacrifícios. Existe uma ideologia subentendida no seio 
Itinerarius

Teflectionis
Revista Eletrônica de Educação do Curso de Pedagogia do Campus Avançado de Jataí da Universidade Federal de Goiás [Vol I - n.2 ] [jan/jul] [ 2006 ]

ISSN: $1807-9342$

das sociedades que precisa ser detectada, tanto pelos indivíduos que a compõem, quanto pelas ciências sociais que se propõem estudar e compreender estas sociedades. Sobre as ciências sociais, eles afirmam que a não compreensão destes determinantes implica sua renúncia como ciência, e ao indivíduo implica a sua individualização. Nesse processo de socialização, para os autores, individualização é a antítese de socialização.

Iniciar este debate apresentando estes autores (Da Matta (1987); Adorno e Horckeimer (1973)) justifica-se principalmente pelo ponto de vista defendido por eles, embasados na teoria marxista de que a formação das sociedades se deu por determinantes históricos; fatores diferenciados formaram diferentes sociedades. No entanto, Adorno e Horckeimer apontam para uma importante questão a ser considerada na esfera da cultura. Eles ressaltam que historicamente as sociedades capitalistas caminham para processos de desestruturação do homem por meio de sua individualização, presente, principalmente, nas ideologias das esferas socializantes do homem, que aqui compreende-se como a cultura, a indústria cultural, a escola. Em seu texto eles não apresentam soluções concretas para essa questão, mas apontam como um alerta a ser considerado, visto que a socialização humana na esfera da sociedade capitalista está mediada por essas determinações aqui mencionadas. Como se daria, então, a socialização do homem nesta sociedade cuja realidade é escamoteada por ideologias e na qual o homem se apresenta individualizado? Como então se efetiva a socialização humana? Que fatores devem ser considerados neste processo? Qual é a representatividade da sociedade nestes determinantes?

\section{2 - A influência da sociedade no processo de socialização humana}

Uma análise da influência da sociedade nos processos de socialização foi elaborada por Berger (1973), na qual ele demonstra que a sociedade é extremamente importante nesse processo, e afirma que "a sociedade constitui as paredes de nosso encarceramento na história". No entanto, acredita-se que, com esta visão fechada, a própria socialização, que implica um movimento na história, estaria comprometida. Posteriormente, o autor ameniza esta afirmativa, relativisando o que ele mesmo denomina de "sombrio determinismo". Mesmo com este determinismo apontado pelo autor, é importante relacionar aqui os fatores abordados por ele e que se constituem como pontos fundamentais no processo de socialização: o homem na sociedade, a sociedade no homem, a sociedade como drama. 
Litinerarius

Teflectionis
Revista Eletrônica de Educação do Curso de Pedagogia do Campus Avançado de Jataí da Universidade Federal de Goiás [Vol I - n.2 ] [jan/jul] [ 2006 ]

ISSN: $1807-9342$

Ao analisar 'o homem na sociedade', Berger (1973) demonstra o quanto a sociedade impõe ao ser humano seus conceitos, padrões, leis e regras, desde a infância. Essa imposição é feita por uma sociedade composta de inúmeras regras e a localização do indivíduo na sociedade constitui uma definição das regras que devem ser obedecidas. A obediência para ele se dará por meio de um controle social e esse controle será exercido em diversas instâncias da vida do indivíduo sendo que, na idade adulta, vai desde a burocracia exercida pela própria sociedade até ao sistema ocupacional do indivíduo; e na infância, desde a escola até o grupo humano no qual a criança está inserida. Para o autor, o grupo familiar é um dos laços sociais mais importantes de um indivíduo e fatores de coerção nesse grupo mais íntimo têm efeito psicológico muito mais sério que em outra instância da comunidade.

O autor ressalta ainda que situar-se em sociedade é posicionar-se em relação a muitas forças repressoras e coercitivas ${ }^{5}$ e estas diferentes forças coercitivas estarão vinculadas à localização do indivíduo em sociedade. Uma área capaz de contribuir com o significado da localização do indivíduo em sociedade é o da estratificação social.

$\mathrm{Na}$ sociedade ocidental, o sistema de classes, segundo Berger, determina as possibilidades ou oportunidades de uma pessoa e o destino que essa pessoa pode esperar ter na sociedade. Para ele, compreender a importância de classes leva o indivíduo não só ao controle social, como também a perceber a maneira como a sociedade influencia sua consciência. $\mathrm{Na}$ maioria das vezes, o sistema de classe é determinado por meios econômicos e, por isto, quase sempre, o indivíduo permanece no mesmo padrão de vida. Em algumas sociedades ressaltadas pelo autor, torna-se impossível a mudança de uma classe à outra; como exemplo desta rigidez, o autor apresenta o sistema racial americano.

Assim, é possível perceber que a sociedade não aceita intercessão de indivíduos de diferentes classes com a mesma facilidade que aceitaria para indivíduos na mesma condição sócio-econômica. Por meio de regras, normas, diferentes determinações são impostas à sociedade pelas classes sociais, bem como pelo credo religioso ao qual a família pertence. No entanto, ressalta o autor, essas pressões nem sempre possuem influências sobre o indivíduo, visto que suas expectativas são exatamente aquilo que a sociedade espera deles. Berger faz, em outro momento,

\footnotetext{
${ }^{5}$ A coerção na sociedade é vista por Levrebvre (1991) como um terrorismo inserido na vida cotidiana. Tanto as leis, as regras, a burocracia existente na sociedade, como a própria linguagem, por meio de um discurso ideológico, se transforma em força coercitivas.
} 
uma análise sobre os tipos de papéis existentes na sociedade e como a sociedade condiciona o indivíduo a ser aquilo que ela espera dele.

No que se refere às imposições dadas pela sociedade, o autor ressalta o papel das instituições na vida do indivíduo como um fator importante no processo de socialização. $\mathrm{Na}$ realidade todas essas regras ou jogos criados pela sociedade fazem parte de uma instituição, que, para Berger, é um complexo específico de ações sociais, sendo a lei, a classe, o casamento, ou a religião instituições organizadas.

Observa-se, então, que a sociedade, como foi dito anteriormente, é uma organização da coletividade. Esta organização se constitui na formação de regras, normas, valores que possibilitam à coletividade sua estruturação social e moral, e, conseqüentemente, sua harmonização como "seres humanos". Mesmo que nesta organização, na estruturação social da sociedade ocidental, prevaleça a ideologia e a coerção de grupos dominantes, ela é fundamental no contexto da vida em sociedade.

Assim, retomando o enfoque sobre 'o homem na sociedade', compreende-se que fatos sociais são externos ao sujeito e que a inserção do indivíduo em determinada sociedade vai determinar seu comportamento tanto biológico quanto social. É neste sentido que, para Berger (1963), a sociedade constitui 'as paredes de nosso encarceramento na história', pois ela é determinante fundamental no processo de socialização.

Ao analisar o papel determinante da 'sociedade no homem', o autor parte da mesma lógica de coerção abordada anteriormente, isto é, a localização social na qual o indivíduo está inserido afeta não só sua conduta, mas também o seu ser. Esta localização social do indivíduo determinará também importantes aspectos de diferenciações culturais, que estarão determinando a concepção de mundo do indivíduo, bem como todo o sistema cultural de seu grupo.

Neste contexto de inserção cultural, analisado por Berger, o indivíduo será aquilo que a sociedade espera dele. Percebe-se que a sua inserção na sociedade é tão forte que o indivíduo não atua de forma diferente, isto é, admite sem conflitos a maioria das imposições culturais criadas ${ }^{6}$,

\footnotetext{
${ }^{6}$ Compreende-se que as imposições culturais impostas ao homem em um contexto histórico e cultural estarão determinando todo o sistema cultural de seu grupo. Neste contexto, Laraia (1989) tem a mesma posição que Berger e Berger (1978), no que se refere às influências exercidas pela sociedade sobre a cultura. Neste sentido, ele aborda a concepção de cultura sob cinco aspectos: a primeira delas é que a cultura condiciona a visão de mundo do homem. Para ele, nossa herança cultural, desenvolvida por inúmeras gerações, condiciona nossa avaliação sobre diferentes culturas e o nosso conceito de cultura formula-se conforme os padrões desenvolvidos em nossa sociedade. $\mathrm{O}$ segundo ponto que ele analisa é o de que a cultura interfere no plano biológico; um exemplo disto é a apatia quando
} 
Ltinerarius

Teflectionis
Revista Eletrônica de Educação do Curso de Pedagogia do Campus Avançado de Jataí da Universidade Federal de Goiás [Vol I - n.2 ] [jan/jul] [ 2006 ]

como é o caso do casamento, que é uma instituição universal, diferenciada em algumas sociedades.

Em todas as situações sociais existem pressões e a sociedade existe porque as definições da maioria das pessoas para situações mais importantes são semelhantes. A sociedade desenvolve papéis semelhantes para cada tipo de conduta, ou "teoria dos papéis". Ao assumir determinada função ou profissão na sociedade, o indivíduo estará agindo conforme o papel que assumiu, tendo sido este papel definido anteriormente pela sociedade como um padrão, definindo também a sua forma de agir, de andar, de falar, de vestir-se. Usando uma conduta diferenciada, a própria sociedade cobraria deste indivíduo este sentimento de postura.

A imposição dos papéis é tão forte que muitas crianças, ao longo de suas vidas, ouvem afirmações como "você não está agindo como um homenzinho". Para Berger (1973), todo papel implica uma identidade - masculina, feminina, identidade de um oficial, de um professor. Porém, segundo ele, esta identidade em uma perspectiva sociológica, é atribuída socialmente, sustentada socialmente e transformada socialmente. O processo pelo qual a sociedade impõe esses papéis e pelo qual uma criança os apreende são determinados pelo autor como socialização.

Dessa forma, a socialização na infância será mediada principalmente pela família, e esta, a seu ver, terá grande influência na construção desta identidade. Vale ressaltar que a família, mediada pela sociedade, influenciará esta socialização, exercendo seu papel coercitivo e ao mesmo tempo, cobrando desta criança sua inserção nos respectivos papéis determinados pela sociedade.

A socialização da criança passa pelo processo de aprender a se portar frente a estes papéis, assim como a assumir o papel do outro. Por isto, Berger (1973) enfatiza a importância da brincadeira na vida da criança. A brincadeira possui uma função sócio-psicológica na qual a criança representa vários papéis sociais e assim descobre o significado dos papéis que lhe são

determinados grupos se vêem, distantes de seu ambiente cultural, perdendo a motivação que os mantêm vivos e unidos. O terceiro ponto levantado por ele é que os indivíduos participam diferentemente de sua cultura. Estas diferenciações estão ligadas a fatores como gênero ou faixa etária. O quarto ponto que Laraia levanta é a lógica. Para ele, todo sistema cultural tem uma lógica própria, não podendo ser transferida de um sistema para outro. Como último ponto, ele salienta a dinamicidade da cultura, dizendo que a própria historicidade humana, séculos após séculos de vida humana e socialização, condiciona as mudanças do sistema cultural. Assim, percebe-se que vários fatores influenciam a concepção de cultura do homem, bem como a própria dinamicidade do momento histórico vivenciado pelas sociedades. São estes fatores que, no âmbito de um determinado grupo social, estarão influenciando a concepção de mundo deste grupo e, portanto, sua socialização. 
atribuídos. Todo este aprendizado só ocorre em interação com outros seres humanos, é neste sentido que o autor afirma que se aprende a ser humano em sociedade.

Ao repensar a 'sociedade no homem' na proposição aqui apresentada, percebe-se que os processos de socialização estarão fortemente vinculados à sociedade e ao papel que a sociedade espera do indivíduo. Esta socialização poderá passar por uma perspectiva, tanto de autonomia do sujeito, quanto de fazer dele um indivíduo cheio de valores pré-determinados, bem como de 'préconceitos' fortemente arraigados. E, como Berger (1973) também aponta, com grande teor de ideologia proposto pelas instituições às quais os indivíduos estão submetidos.

A sociedade pré-define para nós esse mecanismo simbólico fundamental com o qual apreendemos o mundo, ordenamos nossa experiência e interpretamos nossa própria existência (...) fornece nossos valores, nossa lógica e o acervo de informação (ou desinformação) que constitui nosso 'conhecimento'. (BERGER, 1973, p. 132)

Berger (1973) analisa ainda uma outra questão frente às imposições feitas pela sociedade, que ele chama de "teoria do grupo de referência". É o papel representado pela coletividade. Normalmente o indivíduo se une a diferentes grupos similares, no trabalho, na escola, na igreja e, por meio destes grupos, estará sujeito a seguir idéias e ações específicas préestabelecidas pelo grupo. A opinião deste grupo vai afetar as opiniões individuais. Segundo o autor, as opiniões grupais, quando relacionadas às questões étnicas, políticas ou estéticas, exercem força ainda maior ${ }^{7}$.

É, então, neste sentido, que, para o autor, o pensamento sociológico proporciona uma imagem da sociedade atuando no homem. Esses fenômenos sociológicos, segundo Berger, são conhecidos como 'internalização'; a socialização é o mundo social internalizado pela criança. Neste processo aqui apresentado, percebe-se que esta internalização estará sempre mediada pela influência da sociedade, tanto em seus aspectos positivos, quanto em seus aspectos negativos, bem como a interiorização de preconceitos não humanizadores que se formarão neste processo em diferentes subculturas.

Outro ponto de inferência no processo de socialização e que foi abordado por Berger, refere-se à 'sociedade como drama', na qual a sociedade é um palco e os indivíduos são atores sociais. Neste ponto Berger levanta com certo alívio à possibilidade de uma certa liberdade

\footnotetext{
${ }^{7}$ Este mesmo fenômeno social é apontado também por Adorno e Horckeimer (1973) em uma discussão sobre massa, onde os homens imbuídos de um certo conformismo ampliam as predisposições para uma submissão ideológica.
} 
humana em face aos vários determinismos sociais. Dentre os papéis possíveis onde esta liberdade estaria sendo exercida estão aqueles que procuram de alguma forma burlar a sociedade vigente. Dentre eles, segundo o autor, estão os indivíduos que conseguem manipular o sistema de tal forma que as coisas são geradas de acordo com seus interesses; são aqueles que, operando o sistema, desfrutam de mecanismos, de instituições públicas, etc. Há também os vigaristas, impostores e charlatões que, conhecendo o sistema, assumem determinados papéis agindo em benefício próprio. Para ele, estas contra-sociedades, marginalizadas, com definições discordantes, existem na forma de seitas, cultos, 'círculos fechados'- chamados pelos sociólogos de subculturas, que para o autor, são submundos protegidos dos controles físicos e ideológicos da sociedade. São, segundo o autor, impostores que assumem papéis de respeito na sociedade constituindo um embuste da própria realidade. Este tipo de ator social é extremamente comum na sociedade capitalista. Indivíduos que agem diferentemente dos papéis por eles representados.

A sociedade nos oferece nomes para nos proteger do nada. Constrói um mundo para vivermos e assim nos protege do caos em que estamos ilhados. Oferece-nos uma linguagem e significados que tornam esse mundo verossímil. E proporciona um coro firme de vozes que confirmam nossa crença e calam nossas dúvidas latentes (BERGER, 1973, p. 165)

Percebe-se, neste sentido, que a sociedade, ao mesmo tempo em que constrói o mundo do indivíduo, determina como este mundo deve ser vivido, sentido, ou experienciado; e, por meio de ideologias presentes em diversas instâncias da vida social, impõe ao indivíduo uma falsa realidade. Compreender todo este mecanismo de coerção presente nas instituições sociais e nesta sociedade como um todo constitui um papel para um indivíduo consciente. Mas, frente a esta análise apontada por Berger, percebe-se que esta consciência só será possível por meio de uma socialização internalizada em uma cultura universal. Isto é, não mediada por ideologias, mas que confere ao indivíduo um mundo humano construído como um mundo de significações e valores, no qual a cultura sai do domínio da necessidade para o domínio da liberdade e torna possível a comunicação com o outro, em um movimento que impõe à cultura um caráter de universalidade.

\section{2 - Os processos de socialização}


Ztinerarius

Teflectionis
Revista Eletrônica de Educação do Curso de Pedagogia do Campus Avançado de Jataí da Universidade Federal de Goiás [Vol I - n.2 ] [jan/jul] [ 2006 ]

Para se pensar a socialização, considera-se aqui que o homem enquanto ser genérico se socializa nas relações com outros homens e em sociedade. É um processo de interação social, que, para Berger e Luckmann (2001), ocorre na situação de estar face a face com o outro e no convívio com outras pessoas. Esse encontro face a face, segundo os autores, vão gerar os padrões do indivíduo frente ao outro, o que eles designam de tipificações. Estas tipificações já apontadas aqui se referem aos papéis ou tipos assumidos pelos indivíduos na vida cotidiana. Em situações de interação entre os indivíduos, estas tipificações são internalizadas e a realidade da vida cotidiana é apreendida.

Ao analisar o papel da linguagem na vida cotidiana, Berger e Luckmann (1985) afirmam que a expressividade humana é capaz de objetivações, isto é, manifesta-se em produtos da atividade humana. Segundo eles, a produção humana de sinais é um importante fator de objetivação e a linguagem é definida por eles como um sistema de sinais vocais, ou seja, a linguagem é o mais importante sistema de sinais da sociedade humana e a sua compreensão é a essência para a compreensão da realidade da vida cotidiana.

Segundo os autores, a linguagem é essencial no processo de socialização, pois, por meio da linguagem, o indivíduo aprende a transmitir e reter significados, bem como, transmitir de geração a geração suas experiências da vida cotidiana. A linguagem torna-se um dos principais fatores do processo de socialização do indivíduo e a socialização principia a partir da interação e convívio dos indivíduos em sociedade.

A socialização é um processo de interiorização da sociedade, de seus valores culturais, crenças, mitos. Não é um processo fechado de aprendizagem. Por isso pode ocorrer pela criança, a partir de seu nascimento, e pelo adulto, se em dado momento de sua vida mudar, por exemplo, de uma sociedade para outra. Estará mediada pela inserção do homem na sociedade e pela força coercitiva que essa sociedade, por meio das diferentes instituições sociais, exerce sobre ele em diversos momentos de sua vida.

Berger e Luckmann (2001) afirmam que o homem não nasce membro de uma determinada sociedade, mas com predisposição para a sociabilidade e para se tornar membro dessa sociedade. Para os autores, interiorização é o ponto inicial deste processo, a saber, a apreensão ou interpretação imediata de um acontecimento objetivo como dotado de sentido, isto é, a apreensão do mundo como realidade social dotada de sentido. 


\section{1 - Socialização primária e secundária}

Os processos de socialização do individuo estão mediados pela interação do homem com a sociedade. Pode-se considerar que todo esse processo inicia-se desde a gestação da criança por meio da percepção do feto aos estímulos externos, mediados pela mãe. Esta socialização inicia-se então desde a mais tenra idade, estando a criança em convivência inicial com a família e posteriormente com as instituições sociais que compõem a esfera da sociedade.

Para Berger e Luckman (2001), há a socialização primária e secundária. A primária é a primeira socialização que o indivíduo experimenta na infância, e em virtude da qual torna-se membro da sociedade. A secundária é qualquer processo subseqüente que introduz um indivíduo já socializado em novos setores do mundo objetivo de sua sociedade.

A socialização primária é um processo que ocorre na família, todo o mundo social da criança é interiorizado, mediatizado pela família. Terá como base a localização da criança em uma estrutura social maior, isto é, serão interiorizados valores e conhecimentos pertencentes àquele mundo social em que vive. Para os autores, é esta socialização que lhe dará a visão de mundo sobre sua realidade. Importante, portanto, o seu caráter emotivo. Por isso o convívio e a interiorização entre os indivíduos serão sempre carregados de significados.

O indivíduo, ao nascer, encontra-se inserido em uma estrutura social objetiva, rodeada de significados que possibilitam sua socialização. Posteriormentem todo processo de socialização se desenvolve de forma imposta pela realidade objetiva, isto é, a sociedade em suas formas, normas, e valores passa a interferir no processo de socialização que em sua origem estará mediado pelo mundo social no qual o indivíduo está inserido. Para Berger e Luckmann (2001), a socialização primária cria na consciência da criança uma abstração progressiva dos papéis e atitudes dos outros, do particular para o geral, ou seja, ela passa a compreender atitudes individuais como sendo da sociedade, de outros. É a compreensão da universalidade do gesto que possibilitará à criança incorporar em si todos os diferentes papéis e atitudes interiorizadas. Eles apontam essa formação de consciência do outro generalizado como a marca de uma fase decisiva na socialização, o momento em que a criança interioriza a sociedade e a realidade objetiva nela estabelecida.

A realidade objetiva e subjetiva, ainda segundo Berger e Luckmann (2001), se estabelece em relação simétrica quando a percepção do outro estiver cristalizada na consciência 
da criança, possibilitando, assim, que as duas realidades se constituam em uma relação de reciprocidade, isto é, a realidade objetiva se "traduza" em realidade subjetiva. Para que isso ocorra, dizem os autores, é fundamental o papel da linguagem, porque o conteúdo da socialização é determinado pela distribuição social do conhecimento.

Outra questão destacada, sem dúvida, determinante no processo de socialização, referese à identificação do indivíduo com a realidade a ser socializada, que ele acatará sem objeção. Para a criança não há escolha: ela participa de um processo determinado socialmente pela posição de seu nascimento em determinada sociedade e vai se identificar automaticamente com seus significativos. O mundo que é apresentado à criança é o único mundo existente; por esse motivo, o mundo interiorizado na socialização primária torna-se mais forte na consciência da criança do que os mundos interiorizados na socialização secundária.

Diferentes conteúdos podem ser apreendidos na socialização primária. No entanto, para Berger e Luckmann (2001), é a linguagem que deve ser interiorizada, pois, por meio dela, diferentes esquemas interpretativos são interiorizados com valor institucional definido. $\mathrm{O}$ primeiro mundo do indivíduo também é construído na socialização primária; é o momento em que a criança adquire confiança tanto nas pessoas quanto nas situações definidas por essas pessoas, podendo, desta forma, conservar a sua realidade mesmo que se transfira para diferentes regiões.

Outra questão considerada pelos autores na socialização primária refere-se à aprendizagem, que estará definida socialmente em uma seqüência correspondente à idade, isto é, a socialização primária se modifica de uma sociedade para outra, bem como os estágios da aprendizagem, pois o que é definido como infância em uma sociedade pode ser definido como estado adulto em outra. Esta caracterização se processa principalmente pela concepção de infância definida em cada sociedade ${ }^{8}$.

\footnotetext{
${ }^{8}$ Segundo Ariès (1981), na idade média, não existia um sentimento de infância, as crianças permaneciam na companhia dos pais até a idade dos sete anos aproximadamente, para posteriormente serem afastadas e encaminhadas a uma família desconhecida destas crianças, para que aprendessem um determinado ofício. Estas crianças, então, a partir dos sete anos eram consideradas como adultos e a elas eram atribuídas diferentes tarefas, normalmente elas seriam criadas de seus mestres. O aprendizado delas era o desempenho destas determinadas tarefas, nas quais adquiriam o conhecimento do ofício que se tornariam membros da sociedade. Historicamente estas relações das crianças com a família foram se modificando, ao final do século XVII as crianças passaram a permanecer em companhia da família, iniciando aí o 'sentimento de infância', bem como diferentes formas de apreensão do conhecimento e socialização.
} 
Para Berger e Luckmann (2001), a socialização nunca é total nem jamais estará acabada. No entanto, a socialização primária termina quando o conceito do outro foi estabelecido na consciência do indivíduo e o mundo é percebido de forma mais universal. A partir desse momento, a criança é introduzida em um mundo social mais amplo, interioriza submundos institucionais ou baseados em instituições, interioriza conhecimentos gerados no seio da sociedade e por ela institucionalizados.

Para os autores, direta ou indiretamente, a socialização secundária tem suas raízes na divisão do trabalho, porque exige vocabulários específicos de funções e interiorização de campos semânticos que estruturam uma instituição. Ocorre em realidades parciais, contrastando com a socialização primária: “o caráter da socialização secundária dependendo do status do corpo de conhecimento em questão no interior do universo simbólico em totalidade", isto é, há a divisão do trabalho, a divisão do conhecimento, e a divisão do status do conhecimento. Nesse processo de socialização, pressupõe-se um conhecimento anterior do indivíduo, uma personalidade formada anteriormente pela socialização primária, assim como necessidades técnicas diferenciadas conforme o conteúdo a ser aprendido.

Segundo os autores, os limites biológicos são menos importantes na socialização secundária; o aprendizado nesta fase terá uma seqüência lógica; pressupõe uma seqüência, que muitas vezes também precisa de determinados conhecimentos anteriores. Segundo eles,

enquanto a socialização primária não pode ser realizada sem identificação, carregada de emoção, da criança com seus outros significativos, a maior parte da socialização secundária pode dispensar este tipo de identificação mútua incluída em qualquer comunicação de seres humanos. (BERGER E LUCKMANN, 2001, p. 188)

A socialização carregada de emoção sempre estará presente na vida da criança, enquanto a socialização secundária não tem este caráter. A criança aprende com o professor, que representa uma instituição e um contexto social e aprende sobre este mundo. Mas quando volta para casa se desliga deste aprendizado voltando às afinidades da socialização primária. $\mathrm{Na}$ socialização secundária, não haverá este grau de identificação, o conhecimento será racional e emocionalmente controlado.

A socialização secundária também exigirá necessidades técnicas diferenciadas, conforme o conteúdo a ser apreendido e a maior complexidade da distribuição social do 
Ztinerarius

Teflectionis
Revista Eletrônica de Educação do Curso de Pedagogia do Campus Avançado de Jataí da Universidade Federal de Goiás [Vol I - n.2 ] [jan/jul] [ 2006 ]

ISSN: $1807-9342$

conhecimento o que poderão ser sanadas com mais atenção, ou seja, através de professores específicos de determinados conteúdos, com orientação mais sistemática à criança.

Desta forma, compreende-se o quanto o processo de socialização é importante para a formação do indivíduo. Ressalta-se, também, que a socialização é mediatizada pela linguagem, uma das instituições mais importantes de todo o processo. Considerando esse caráter infere-se que a socialização secundária se efetiva fora da esfera familiar, no contato das crianças com outros membros da sociedade e/ou instituições. Ao longo da história da humanidade essa socialização se modifica, sendo o trabalho uma importante esfera nesse processo. Vários espaços e instituições podem ser considerados como determinantes: a escola, a família, a religião, os grupos sociais, os partidos políticos, entre outros. Nessa perspectiva, pode-se afirmar que a socialização é educação e educação é socialização.

\section{2 - Escola e socialização}

Nesse processo educativo, a escola - que se constitui num dos campos dessa mediação seria uma continuidade. Mas o processo de socialização da criança tem sido considerado como se iniciasse a partir da inserção da criança na escola. Segundo Miranda (1985), os estudos nessa área têm merecido a atenção de diferentes pesquisadores. No entanto, são apresentados com diferentes enfoques teóricos metodológicos que tomam por base concepções referendadas historicamente sem questioná-las ou redefini-las, como, por exemplo, a idéia de infância, a finalidade da escola, as relações entre a criança, a escola e a sociedade e, por fim, o próprio processo de socialização.

Segundo a autora, existe uma ausência de criticidade nas relações da criança com a escola, na qual a criança está sendo destituída de seu papel histórico social. Para se compreenderem os determinantes históricos que influenciam na socialização escolar, propõe uma reflexão da condição de ser criança, demonstrando historicamente como essa idéia se redefiniu a partir das transformações ocorridas nas relações sociais de produção da sociedade industrial. Essas transformações foram percebidas principalmente na concepção da família, isto é, como as famílias concebiam esta idéia de infância na Idade Média e nos tempos modernos.

Anteriormente à sociedade industrial, segundo Miranda (1985), a duração da infância se limitava a tenra idade em que ela necessitava de cuidados físicos para sobreviver. A partir dos sete anos, a criança passava a conviver com o mundo adulto, a socialização acontecia no convívio 
itinerarius

Teflectionis
Revista Eletrônica de Educação do Curso de Pedagogia do Campus Avançado de Jataí da Universidade Federal de Goiás [Vol I - n.2 ] [jan/jul] [ 2006 ]

com a sociedade, não sendo determinada ou controlada pela unidade familiar. As reflexões desta autora centram-se teoricamente em Ariès (1981) que faz esta análise, da ausência do sentimento de infância desde a Idade Média, apontando historicamente como este sentimento veio surgindo gradativamente após o século XVII.

A família moderna, segundo a autora, estabelece-se com a burguesia a partir do séc. XVIII. As relações familiares se modificam instalando uma intimidade entre as famílias, uma vida privada consolidando novas determinações. A aprendizagem social, segundo Miranda (1985), foi deixando de se realizar no convívio direto com os adultos e foi substituída pela educação. Apresentou-se, assim, o sentimento moderno de família. A criança da família burguesa passou a ser educada em colégio e a alta nobreza e os povos conservam por mais tempo os antigos padrões.

Ademais, diferentes fatos históricos definiram diferentes contextos para a idéia moderna de infância cujos determinantes históricos são desconhecidos e suprimidos atualmente. Em conseqüência, segundo Miranda (1985), é dissimulada a dimensão social da relação da criança com o adulto e a sociedade. A escola reproduz uma concepção de infância, natural e abstrata, desconsiderando a criança concreta, socialmente determinada em um contexto de classes sociais antagônicas.

Todos os processos de socialização pelo qual a criança passou desde a socialização primária são desconsiderados. Miranda (1985) aponta essa questão em outras esferas da sociedade antes de a criança chegar a escola. No discurso escolar, segundo a autora, essa socialização é desconsiderada e a sua função é atribuída à escola que, nesse contexto, é concebida com função de integração da criança à sociedade.

Veja que a idéia de infância foi se modificando historicamente e a criança foi separada da esfera familiar e do convívio do adulto em função das relações sociais de produção. Para Miranda (1985), a família burguesa atribui esta função de educar à escola. Paulatinamente a criança perdeu seu papel social, passando a ser percebida como ser natural biologicamente frágil, que, para ser reintegrada ao mundo social de produção capitalista, precisa ser socializada pela escola.

Se a criança já é socializada pela família na socialização primária, e por diferentes instâncias da sociedade de acordo com seu mundo ou classe social, chega à escola, na socialização secundária, já socializada. Essa socialização não é integradora e a escola deve 
compreender a dialética das relações entre a criança e a sociedade, numa perspectiva de totalidade e historicidade (MIRANDA, 1985). O processo de socialização da criança é um processo evolutivo e, se a socialização inicia-se antes da escolarização, portanto, não há necessidade de reintegração.

Segundo Ariès (1981), após a Idade Média, quando retornaram ao seio familiar, as crianças, não sendo consideradas como um ser social, passaram por uma fase denominada pelo autor de 'paparicação'. Tudo que faziam era para distrair os adultos, que as achavam "bonitinhas". Por meio da expressão desse sentimento, os educadores e moralistas da época acreditavam que as crianças se tornavam mal-educadas e mimadas e defenderam sua inclusão na escola. O processo que se seguiu retirou as crianças novamente do convívio familiar para que fossem enclausuradas nos colégios internos. Por esse motivo, elas se distanciaram do convívio com os adultos e com a sociedade.

Como conseqüência a escola procurou se defender com a função socializadora. No entanto, como afirma Miranda (1985), a escola desconsiderou tanto as determinações históricas quanto o fato de a criança já ser socializada, pois, no convívio familiar, ela já internaliza padrões de comportamentos, normas e valores de sua realização social. Este processo inicial de socialização, como já foi dito, ocorre pela mediação do outro, que, neste caso, é familiar, e estabelecerá vínculos essenciais entre a criança e o mundo social, possibilitando a internalização desses valores.

Percebe-se, neste contexto, que a escola, considerando a historicidade da criança e sua socialização anteriores à escola, estaria dando ao processo inicial de socialização legitimidade, possibilitando à criança maior possibilidade de novos padrões de socialização, e conseqüentemente menos problemas de aprendizagem.

Considerando-se os problemas que surgem no contexto educacional, percebe-se que muitos deles são provenientes da distância existente entre as questões teóricas e práticas da educação. Para Bruner (2001), é necessário se pensar como chegar até as crianças - como os seres humanos atingem um encontro de mentes, isto é, como se processa a interação entre os seres humanos que possibilita a aprendizagem. O estudo que se propõe a discutir estas questões é chamado pelo autor de "psicologia popular". Com isto, ele enfatiza a necessidade de se levar em consideração as teorias populares ao se elaborar teorias sobre a prática na sala de aula, pois estas 
itinerarius

Teflectionis
Revista Eletrônica de Educação do Curso de Pedagogia do Campus Avançado de Jataí da Universidade Federal de Goiás [Vol I - n.2 ] [jan/jul] [ 2006 ]

teorias estão arraigadas na sala de aula e, para se conseguir alguma mudança, deve-se conhecêlas.

As teorias mencionadas pelo autor são as concepções que se constituem em estereótipos de educadores e de escolas que desconsideram a historicidade mencionada por Miranda e Ariès. Isto é, ao desconsiderar a historicidade da criança, desconsidera-se também a produção teórica que constitui a análise desta historicidade.

Para Bruner (2001), ensinar baseia-se em noções sobre a natureza da mente de quem aprende. $\mathrm{O}$ ato de ensinar, segundo ele, ocorre em diferentes culturas em uma grande variedade, sendo pois, necessário conhecer e saber sobre essa diversidade. Caso contrário, os pedagogos populares acabam por orientar a forma de o professor ensinar e refletir sobre uma série de pressupostos sobre as crianças, muitas vezes errôneos.

Desta forma, o autor ressalta que a tese que emerge das práticas educacionais na sala de aula baseia-se em um conjunto de crenças populares sobre as mentes dos alunos podendo ser percebidas ora positivamente ora negativamente contra o bem estar das crianças. Todo este processo de aprendizagem, diz o autor, envolve diferentes questões, pois essas crianças pequenas estão inseridas em família e comunidades, que se esforçam para conciliar suas crenças, desejos e objetivos com o mundo à sua volta. Neste sentido, Bruner (2001) enfatiza que compreender de onde vem o conhecimento talvez seja a chave para se conhecer o que é cultura.

Neste sentido, a pedagogia popular, teoria apontada pelo autor, considera que o ensino deveria ajudar as crianças a compreenderem a distinção entre o conhecimento pessoal e o conhecimento da cultura. Além de perceber esta distinção, as crianças deveriam também entender sua fundamentação na história do conhecimento.

Ao enfatizar o conhecimento do passado e a contribuição que os diferentes autores do passado dariam ao presente por meio de um discurso, o autor conclui que a criança, como um ser ativo e intencional, compreende que o conhecimento sobre o mundo e sobre nós e os outros é construído e negociado com os outros - os autores.

Assim, além de possibilitar a criança novos conhecimentos sobre o mundo em que vive, estaria também possibilitando a construção deste conhecimento, não em cima de estereótipos arraigados, mas por meio da história da própria socialização - a socialização da humanidade, que, a saber, foi construída historicamente. 
Litinerarius

Teflectionis
Revista Eletrônica de Educação do Curso de Pedagogia do Campus Avançado de Jataí da Universidade Federal de Goiás [Vol I - n.2 ] [jan/jul] [ 2006 ]

Após as reflexões aqui apresentadas sobre os processos de socialização, compreende-se que a internalização da cultura se efetiva nessa socialização. A criança, em contato com as diferentes determinações históricas e sociais, apreenderá os valores, os conceitos, as tipificações que a sociedade lhe estipulou a ser seguida, os conhecimentos gerados pela humanidade e que lhe foram apresentados como conteúdos construídos historicamente. Sua identidade se firmará no contexto cultural de sua sociedade e a internalização destes valores sociais e culturais se estabelecerá na relação de consciência da criança consigo mesma e com os outros.

A socialização humana é complexa, principalmente quando se percebe que a história da humanidade parece andar na contra mão de uma formação humana, isto é, de um 'ser humano' (Adorno e Horckeimer, 1973). Isto pode ser afirmado quando a influência da ideologia, no contexto das sociedades capitalistas, é analisada, assim como todo o processo de socialização mediatizado por esta sociedade.

Talvez seja necessário relembrar aqui o 'determinismo sombrio' mencionado por Berger, quando aponta a influência da sociedade no homem, mas talvez seja mais prudente buscar na história da humanidade o momento em que o homem adquire consciência de si e do outro. Este momento está na externalização da cultura, tanto objetiva quanto subjetiva, pois, somente aí, pode-se empreender a verdadeira oportunidade de socialização, pois se compreende que a socialização do homem enquanto 'humano' se efetiva na internalização da cultura, na sua universalidade. 


\section{3 - Bibliografia}

ADORNO, T. W. e HORKHEIMER, M. Temas básicos da sociologia. Trad. de Álvaro Cabral. São Paulo: Cultrix e Editora da USP, 1973. ARIÈS, Philippe. História social da criança e da família. 2 ed. Rio de Janeiro, RJ: Livros Técnicos e Científicos, 1981.

BERGER, Peter L. Perspectivas sociológicas: uma visão humanística. Petrópolis: Vozes, 1973. e BERGER, Bigitte. O que é uma instituição social? In: FORACCHI, Marialice Mencarini e MARTINS, José de Souza. Sociologia e sociedade: leituras de introdução à sociologia. Rio de Janeiro: Livros Técnicos e Científicos, 1978.

e BERGER, Bigitte. Socializaçao: como ser um membro da sociedade. In: FORACCHI, Marialice Mencarini e MARTINS, José de Souza. Sociologia e sociedade: leituras de introdução à sociologia. Rio de Janeiro: Livros Técnicos e Científicos, 1978.

BERGER, Peter L. e LUCKMANN, Thomas. A construção social da realidade. Trad. de Floriano Souza Fernandes. 20. ed. Petrópolis, Vozes, 2001.

BRANDÃO, Carlos Rodrigues. Sobre teias e tramas de aprender e ensinar: anotações a respeito de uma antropologia da educação. In: Interação: revista da Faculdade de Educação / UFG. n. 1 / Janeiro, Junho/ 2001.

BRUNER, Jerome. A cultura da educação. Porto Alegre: Artmed, 2001.

DA MATTA, Roberto. Relativisando: uma introdução à antropologia social. 2 ed. Rio de Janeiro: Rocco, 1987.

LEFREBVRE, Henri. A vida cotidiana no mundo moderno. Trad. Alcides João de Barros. São Paulo: Ática, 1991.

MIRANDA, Marília Gouveia. O processo de socialização na escola: a evolução da condição social da criança. In: Psicologia social: o homem em movimento. LANE, Silvia e CODO, Wanderley (org.) 2 ed. São Paulo: Brasiliense, 1995. p. 125 - 135.

VAZ S. J., Henrique de Lima. Cultura e universidade. Petrópolis, RJ: Vozes, 1966. (Coleção educar para a vida. V. 10). 
Revista Eletrônica de Educação do Curso de Pedagogia do Campus Avançado de Jataí da Universidade Federal de Goiás [Vol I - n.2 ] [jan/jul] [ 2006 ]

ISSN: 1807-9342 